\title{
Symptoms of irritable bowel syndrome in ulcerative colitis in remission
}

\author{
B ISGAR, M HARMAN, M D KAYE, AND P J WHORWELL \\ From the Departments of Medicine, Southampton General Hospital, Southampton, University of Vermont, \\ USA, and University Hospital of South Manchester, Manchester
}

SUMMAR厂 The prevalence of symptoms suggestive of a motility disturbance similar to the irritable bowel syndrome was investigated in 98 patients with ulcerative colitis in remission, and a similar number of age- and sex-matched healthy controls. Thirty-three per cent of patients compared with $7 c^{\prime} c$ of controls fulfilled the criteria for such a syndrome $(p<() \cdot() 1)$. Contrary to expectations these symptoms were not confined to patients with distal disease. Other symptoms such as constipation were also very common in the colitic group (31\%).

The clinical diagnosis of the irritable bowel syndrome is based primarily upon the presence of pain associated with a disturbance in bowel habit. Such disturbance may lead to a variety of different symptoms. For our study, we have selected those (Table 1) shown by Manning et al to have the greatest discriminant value.

The diagnosis rests also upon the exclusion of any other pathological process and hence it would be ruled out in the presence of diseases such as ulcerative colitis. Thus if patients with ulcerative colitis were suffering from a motility problem similar to the irritable bowel syndrome the symptoms therefrom might be attributed to their colitis and inappropriately treated. It was the purpose of this study to assess whether patients with ulcerative colitis in remission. as compared with a group of healthy controls. have any evidence of a motility disorder which in different circumstances might be called the irritable bowel syndrome. To avoid confusion we will use the term irritable bowel-like syndrome.

\section{Methods}

PATIENTS

Ninety-eight patients with ulcerative colitis $(52$ women and 46 men. age range $21-85$ years) and 98 healthy controls obtained from local industries and matched for age. sex. and social class were

Address for correspondence: Dr P J Whorwell. Department of Medicine. University Hospital of South Manchester. Manchester M20 8LR.

Received for publication 1 June 1982
Table 1 Simptoms characteristic of irritable bowel syndrome in paticnts and age'-se'x matched controls

\begin{tabular}{|c|c|c|c|c|c|}
\hline \multirow[b]{2}{*}{ Simptom } & \multicolumn{2}{|c|}{$\begin{array}{l}\text { Patic'nts } \\
(n=98)\end{array}$} & \multicolumn{2}{|c|}{$\begin{array}{l}\text { (omtrols } \\
(n=98)\end{array}$} & \multirow{2}{*}{$\begin{array}{l}\text { corrected } \\
\text { pialue }\end{array}$} \\
\hline & $(n o)$. & $(\ddot{i})$ & (no) & $(r i)$ & \\
\hline 1 Abdominal pain & 41 & $41 \cdot 8$ & 18 & $18 \cdot 4$ & $<() \cdot()(0)(15$ \\
\hline $\begin{array}{l}2 \text { More frequent stools when } \\
\text { pain present }\end{array}$ & $2(1$ & $2(1 \cdot 4$ & 5 & $5 \cdot 1$ & NS \\
\hline $\begin{array}{l}3 \text { Looser stools when } \\
\text { pain present }\end{array}$ & 26 & $26 \cdot 5$ & 7 & $7 \cdot 1$ & NS \\
\hline $\begin{array}{l}+ \text { Pain relicf with } \\
\text { howcl action }\end{array}$ & 33 & 3.3 .7 & 8 & $8 \cdot 2$ & $<0.105$ \\
\hline 5 Abdominal distension & 43 & 43.9 & 20 & 2()$\cdot 4$ & $<(1) \cdot()(0)(15$ \\
\hline 6 Incomplete cracuation & 47 & 48.0 & 7 & $7 \cdot 1$ & $<(1) \cdot(0)(0) 5$ \\
\hline 7 Constipation & 31 & $31 \cdot 6$ & 22 & $22 \cdot 4$ & NS \\
\hline$\&$ Diarrhoca & 27 & $27 \cdot 6$ & 9 & $9 \cdot 2$ & $<() \cdot()() 1$ \\
\hline y Nausca & 23 & $23 \cdot 5$ & 4 & $4 \cdot 1$ & $<(1) \cdot(x)(0) 5$ \\
\hline
\end{tabular}

questioned by one investigator and the answers entered on a standard questionnaire. Social class was established using the classification of occupations (1970) published by the Office of Population Censuses and Surveys. ${ }^{2}$

In addition to the usual biographical data, details of duration. extent. and severity of ulcerative colitis were recorded. Patients were asked whether, when otherwise well and in remission, they experience any symptoms of the irritable bowel-like syndrome more than once a week. ignoring any symptoms they experienced in relapse. The passage of mucus was taken as indicating activity of colitis and was thus not acceptable in remission. In addition, patients were judged as being in remission only if they were 
off all medication except maintenance sulphasalazine. At the time of questioning it was noted whether patients were in remission sigmoidoscopically as judged by the absence of blood. mucus. or contact bleeding. Mild granularity was allowable. Ninety per cent of patients met these criteria for remission.

All data were transferred to punch cards and processed on an ICL 2970) computer using the statistical package for the social sciences version 7 . The statistical methods used were the frequency analysis routine and cross-tabulated routine. The latter produced chi-squared values for multifaceted variables.

\section{Results}

Table 1 shows the prevalence of symptoms of the irritable bowel-like syndrome in patients and healthy controls. Pain, pain relief with bowel action. abdominal distension, incomplete evacuation. nausea, and diarrhoea were all significantly more common in ulcerative colitis. It should be noted also that constipation was more common in ulcerative colitis although the difference between groups was not statistically significant.

Forty-one patients and 18 controls had abdominal pain, which may be taken as a prerequisite for irritable bowel-like syndrome. To diagnose a motility problem more definitely other symptoms should be present and Table 2 lists the numbers of patients showing symptoms 2-6 from Table 1 . Diarrhoea was omitted as its inclusion might have biased the figures in favour of ulcerative colitis. There is some debate about whether nausea and constipation are indicative of the irritable bowel syndrome and consequently these symptoms were also disregarded, although they were far more common in patients than controls. For the purpose

Table 2 Symptoms suggestive of irritable bowel disease in controls and patients with ulcerative colitis complaining of abdominal pain*

\begin{tabular}{lcl}
\hline $\begin{array}{l}\text { Number of symptoms } \\
\text { in addition io pain }\end{array}$ & Patients $(n=41)$ & Controls $(n=18)$ \\
\hline 0 & 1 & 4 \\
1 & 2 & 5 \\
2 & 5 & 2 \\
Irritablc bowcl-like syndrome & \\
3 & 16 & 3 \\
4 & 10 & 3 \\
5 & 7 & 1 \\
Total & 33 & $7 \mathrm{p}<0 \cdot(0)$ \\
\hline
\end{tabular}

* Three or more symptoms have been taken as indicating an irritable bowel-like syndrome motility problem of analysis, the combination of pain with three or more svmptoms was taken to indicate the irritable bowel-like svndrome. Using this criterion. the latter was present in 33 patients and seven controls $(\mathrm{p}<() \cdot() 1:$ Table 2).

Of the 33 ulcerative colitis patients with irritable bowel-like syndrome $51 \%$ had distal colitis. $27 \%$ had half the colon involved. and 22\% had total colitis. There appeared to be no relationship between the irritable bowel-like svndrome and the duration or activity of disease: and those subjects with remission of long duration were just as likely to suffer from this disorder.

\section{Discussion}

Recently, Thompson and Heaton ${ }^{3}$ reported a $13 \%$ incidence of symptoms of the irritable bowel syndrome in an apparently healthy population. The results for our control subjects were approximately similar $(7 \%)$. More importantly, our study shows that many patients with ulcerative colitis have symptoms compatible with a diagnosis of irritable bowel syndrome $(33 \%)$.

Certain symptoms included in our questionnaire, such as relief of pain by defaecation, are common to both disorders. It could be argued that the inclusion of such symptoms in our analysis might have artificially inflated the prevalence of irritable bowellike syndrome in our patients with ulcerative colitis. We would stress, therefore, that patients were encouraged to focus upon periods of remission from colitis during formulation of their answers to the questionnaire, and that $90 \%$ of them were, by sigmoidoscopy, in remission at the time they completed the latter. Moreover, other symptoms common in irritable bowel syndrome but not usually considered typical of ulcerative colitis, such as abdominal distension and constipation, were frequent in our colitic group.

One explanation of our findings could be that patients were taking a lower roughage diet than the controls. A full dietary assessment was not made but roughage intake was assessed in all subjects as either high, average, or low, and there was no difference between the two groups, making this explanation untenable. Although it is unlikely that colonic spasm is related to the genesis of ulcerative colitis, previous inflammatory disease of the colon may render it more sensitive and thereby reduce its threshold to such stimuli as distension.

Although the treatment of irritable bowel syndrome is not uniform, it is generally agreed that bulking agents are helpful. ${ }^{4}$ From the results of our study it would seem that the regular use of such agents should be seriously considered in the 
management of patients with ulcerative colitis in whom symptoms persist during periods of remission. This applies particularly to those with constipation. which was present in a third of our patients.

\section{References}

1 Manning AP. Thompson WG. Heaton KW. Morris AF. Towards positive diagnosis of the irritable bowel. Br Med J 1978: 2: 653-4.
2 Office of Population Censuses and Surveys. Classifications of occupations. London: HMSO. 1970.

3 Thompson WG. Heaton KW. Functional bowel disorders in apparently healthy people. Gastroenterology 1980: 79: 283-8.

4 Manning A. Heaton KW. Harvey RF. Uglow P. Wheat fibre and irritable bowel syndrome. Lancet 1977: 2: 417-8.

5 Ritchie JA. Truelove SC. Treatment of irritable bowel syndrome with lorazepam. hyoscine butylbromide and ispaghula husk. $\mathrm{Br}$ Med J 1979; 1: 376-8. 